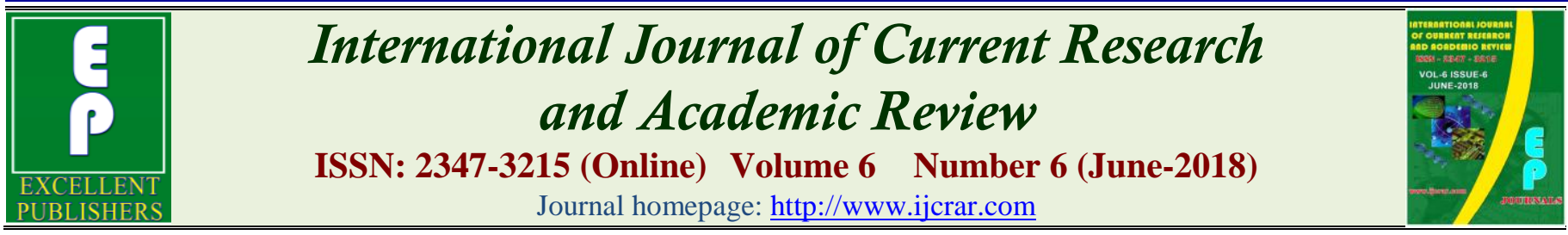

doi: https://doi.org/10.20546/ijcrar.2018.606.009

\title{
Investigation of the Effect of Conducted Therapy on the State of the Immune System in Patients with Cutaneous Leishmaniasis
}

\author{
I. R. Raximov* \\ SO “Republican Specialized Scientific Practical Medical Center of Dermatovenerology and Cosmetology" of the \\ Ministry of Health of $R U$, Uzbekistan
}

*Corresponding author

\section{Abstract}

The study of changes in some indices of the immune system in application of a pathogenetically valid method of treatment using Mexidol and Fargals in patients with cutaneous leishmaniasis. Clinical examination was conducted in 112 patients with cutaneous leishmaniasis. Immunological methods of the research included: determination of markers of immunocompetent cells conducted by the method of indirect rosette formation, as well as determination of concentration of serum Ig classes of A, M, G were determined by the method of Mancini G. and circulating immune complexes (CIC) in blood serum - by the M Digeon method. As a result of the study, it was found that in patients with severe clinical forms of cutaneous leishmaniasis after the use of traditional therapy, the percentage of certain immunocompetent cells (CD3-, CD4-) was prone to increase ( $>>0.05$ ), and with complex therapy, there was a significant increase of the relative number of CD3 cells $(p<0.01)$ and CD4 cells $(p<0.05)$ compared to pre-treatment data. And the relative content of CD8 cells in both treatment methods remained at the data level before the treatment $(\mathrm{p}>0.05)$. With regard to serum immunoglobulins, it was observed that a statistically significant decrease in the concentration of $\operatorname{IgA}$ and $\operatorname{IgG}$ $(p<0.05)$ in relation to the data before treatment was observed in patients receiving the complex therapy, and the amount of $\operatorname{IgM}$ remained unchanged $(\mathrm{p}>0.05)$. The result of applying the complex method of treatment using Mexidol and Fargals in patients with mild clinical forms (tubercle) leishmaniasis has a positive effect by restoring the detected disorders in the immune system and regressing pathological elements on the skin. In case of severe forms (ulcerated) disease, this method of treatment of complete recovery of disorders in the immunity system does not have and this indicates the need for a repeated course of therapy in this category of patients.
\end{abstract}

Article Info

Accepted: 28 May 2018

Available Online: 20 June 2018

\section{Keywords}

Cutaneous leishmaniasis, immunity, immunomodulators

\section{Introduction}

Leishmaniasis still remains one of the most neglected diseases in the world, affecting mainly the poorest of the poor, mainly in developing countries; it is estimated that 350 million people are at risk of becoming infected with leishmaniasis, and about 2 million new cases are diagnosed each year [Fighting against leishmaniasis,
2010]. The main endemic areas in Central Asia are located in Uzbekistan and Turkmenistan [Ponirovsky, 1993; Strelkova et al., 1993], as well as in some regions of Kazakhstan [Djumagulov, 1989]. In these territories, the degree of manifestation of the disease is different and the incidence of the population in each of them has its own characteristic features, due to the interposition of settlements and natural areas, the degree of population's 
contact with focal areas and the level of the immune layer [Abidova and Ikramova, 2014; Abidova et al., 2014; Abidova et al., 2017; Ponirovsky et al., 2016].

To date, the search for new effective drugs for treatment of patients with cutaneous leishmaniasis is a very actual issue [Buffet et al., 1994; Olliaro Brycesson, 1993]. Previously successfully used medications, in particular monomycin, were discontinued, antimony preparations are highly toxic, etc. It should be noted that a variety of surgical, chemotherapeutic, immunobiological and many other methods are used to treat cutaneous leishmaniasis, which can cause serious complications. In view of this, the development of pathogenetically grounded new methods of therapeutic influence is an actual task of modern dermatology.

\section{Materials and Methods}

Depending on the conducted treatment, patients were divided into two groups: the first group (traditional group) consisted of 41 patients constituting the comparison group and receiving basic therapy (vitamins, antimalarial drugs, hepatotropic drugs, antifungal drugs) and local-disinfecting and accelerating epithelialization means; the second group (complex therapy) included 71 patients, making up the main group, which, against the background of traditional therapy, was prescribed the "Mexidol" drug and locally in the form of applications "FarGals". 38 patients with tuberculous skin leishmaniasis (14 patients received traditional and 24 complex therapies), 52 with ulcerated leishmanias (21 patients received traditional and 31 complex therapy) and 22 patients with ulcerated leishmanias with tubercles of seeding with lymphangitis (6 patients received traditional and 16 - complex therapy).

The state of the immune system was assessed by the expression of CD-differentiation and activation antigens. Determination of markers of immunocompetent cells was carried out by indirect rosette formation with the use of an immunoreagent - human 0 (I) erythrocytes of the $\mathrm{Rh}$ group loaded through a 3\% solution of chloric chromium with monoclonal antibodies of CD3 specificity for T-lymphocyte receptors, CD4 for Thelpers/inducers, CD8 - for T-suppressors/cytotoxic lymphocytes, CD19 - for B-lymphocytes [Zalaliyeva, 2004].

The concentration of serum immunoglobulins (Ig) of classes A, M, G was determined by the method of [Mancini et al., 1965] and the number of circulating immune complexes (CIC) in blood serum - by the method of M. Digeon [Digeon et al., 1977].

The results of the study were statistically processed using standard methods of variational statistics using the Student's t-test on the "Excel-Office-2010" application program on a Pentium IV computer.

\section{Results and Discussion}

In previous studies, we found that patients with cutaneous leishmaniasis have an immunodeficiency state. In connection with this, we studied the dynamics of changes in immunological parameters in patients after treatment.

Taking into account the abovementioned, we used the "Mexidol" drug to restore the revealed disorders in the immune system to the complex of therapy for patients with cutaneous leishmaniasis and locally used the "FarGals" drug to accelerate the healing of wounds.

Mexidol (2-ethyl-6-methyl-3-hydroxypyridine succinate) was developed by the Institute of Biochemical Physics named after N.M. Emanuel, the Scientific Research Institute of Pharmacology of the Russian Academy of Medical Sciences and the All-Union Scientific Center for the Safety of Biologically Active Substances. Mexidol is an inhibitor of free radical processes, a membrane protector. The drug improves microcirculation and rheological properties of blood, reduces platelet aggregation, which has an antitoxic effect and increases the regenerative potential of tissues.

FarGals was developed for the first time in Uzbekistan, the composition of the drug is aqueous extract from the medium of cultivation of autotrophic iron-oxidizing bacteria. It has a pronounced antimicrobial effect and reliable wound healing activity.

Meksidol was used intramuscularly at $100 \mathrm{mg}$ twice a day for 14 days.

FarGals: locally in the form of applications, in dilution with distilled water in a ratio of 1: 1,2 times a day for 20 days.

The results of the study showed (Table 1) that in patients with tubercle form of cutaneous leishmaniasis after a traditional therapy, the percentage of CD3 cells and CD4 cells were prone to increase ( $p>0.05)$, and with complex therapy, a significant increase in the relative amount 
CD3 cells $(\mathrm{p}<0.01)$ and CD4 cells $(\mathrm{p}<0.05)$ compared with pre-treatment data. And the relative content of CD8 cells in both treatment methods remained at the data level before treatment $(\mathrm{p}>0.05)$

IRI in patients treated with the traditional method rose from $1.75 \pm 0.09$ to $1.83 \pm 0.07$ after treatment, and in patients receiving the method of therapy developed by us, this index increased from $1.82 \pm 0.04$ to $2.08 \pm 0.06$ and reached the level of control $(2.04 \pm 0.05)$.

As a result of the traditional treatment, a decrease in the relative number of CD19 cells was observed in patients with tubercle cutaneous leishmaniasis compared with pre-treatment data $(\mathrm{p}>0.05)$. And in patients who received complex treatment after the therapy, a significant decrease in the relative number of CD19 cells was detected $(\mathrm{p}<0.01)$.

A study of the concentration of serum immunoglobulins showed that after completion of the traditional method of treatment in patients with tubercle cutaneous leishmaniasis, the level of $\operatorname{IgA} \operatorname{IgM}$ and $\operatorname{IgG}$ remained at the level of the data at admission ( $p>0.05$ ). Patients who received the treatment method developed by us had a statistically significant decrease in the concentration of $\operatorname{IgA}$ and $\operatorname{IgG}(\mathrm{p}<0.05)$ in relation to the data before treatment, and the amount of $\operatorname{IgM}$ remained unchanged $(\mathrm{p}>0.05)$.

Along with this, in both groups there is a significant decrease in the serum concentration of the CIC in comparison with the data before the treatment $(\mathrm{p}<0.01)$.

The obtained data testify that the method of treatment of patients with tubercle form of cutaneous leishmaniasis developed by us has a more effective immunomodulating effect on the indices of the immunity system than traditional therapy.

In patients with ulcerated leishmanias against the background of traditional therapy, there was a tendency to increase the relative content of CD3 cells and CD4 cells ( $p>0.05)$, and in complex therapy a statistically significant increase in the percentage of CD3 cells and CD4 cells was found in comparison with data before treatment $(p<0.05)$. In patients of this group, the relative number of CD8 cells after the treatment, both with traditional and complex therapy, remained at the data level before treatment $(\mathrm{p}>0.05)$ (Table 2).

Table.1 The effect of the conducted therapy on immune status in patients with

Tubercle cutaneous leishmaniasis $(\mathrm{M} \pm \mathrm{m})$

\begin{tabular}{|c|c|c|}
\hline \multirow{2}{*}{ Indices of immunity } & \multicolumn{2}{|l|}{ Method of therapy } \\
\hline & Traditional therapy $n=14$ & Complex therapy $n=24$ \\
\hline \multirow{2}{*}{$\mathrm{CD} 3, \%$} & $52,14 \pm 0,60$ & $51,83 \pm 0,55$ \\
\hline & $52,93 \pm 0,54$ & $56,37 \pm 0,45^{* *}$ \\
\hline \multirow{2}{*}{ CD19, \% } & $19,50 \pm 0,91$ & $19,58 \pm 0,66$ \\
\hline & $18,50 \pm 0,69$ & $16,50 \pm 0,45^{* *}$ \\
\hline \multirow{2}{*}{$\mathrm{CD} 4, \%$} & $32,93 \pm 0,62$ & $34,54 \pm 0,77$ \\
\hline & $34,14 \pm 0,66$ & $36,96 \pm 0,52^{*}$ \\
\hline \multirow{2}{*}{$\mathrm{CD} 8, \%$} & $19,21 \pm 0,78$ & $19,08 \pm 0,51$ \\
\hline & $18,64 \pm 0,49$ & $17,87 \pm 0,37$ \\
\hline \multirow{2}{*}{ IRI } & $1,75 \pm 0,09$ & $1,82 \pm 0,04$ \\
\hline & $1,83 \pm 0,07$ & $2,08 \pm 0,06^{*}$ \\
\hline \multirow{2}{*}{$\operatorname{Ig} \mathrm{A}, \mathrm{g} / 1$} & $2,76 \pm 0,08$ & $2,68 \pm 0,05$ \\
\hline & $2,62 \pm 0,07$ & $2,21 \pm 0,07 *$ \\
\hline \multirow{2}{*}{$\operatorname{IgM}, \mathrm{g} / \mathrm{l}$} & $1,73 \pm 0,04$ & $1,62 \pm 0,03$ \\
\hline & $1,61 \pm 0,03$ & $1,44 \pm 0,04$ \\
\hline \multirow{2}{*}{$\mathrm{IgG}, \mathrm{g} / \mathrm{l}$} & $18,47 \pm 0,79$ & $17,92 \pm 0,48$ \\
\hline & $17,74 \pm 0,58$ & $13,54 \pm 0,56^{*}$ \\
\hline \multirow{2}{*}{ CIC, y.e. } & $23,93 \pm 1,11$ & $27,17 \pm 1,06$ \\
\hline & $19,07 \pm 0,97 *$ & $18,00 \pm 0,70 * *$ \\
\hline
\end{tabular}

Note: in the numerator - data before treatment; In denominators - data after treatment

$\mathrm{p}-$ reliability of data with respect to indicators before treatment; $*_{-} \mathrm{p}<0,05 ; \quad *_{-} \mathrm{p}<0,01$ 
Table.2 The effect of therapy on immune status in patients with ulcerated leishmanias $(M \pm m)$

\begin{tabular}{|l|c|c|}
\hline \multirow{2}{*}{ Indices of immunity } & Method of therapy & \multicolumn{2}{|l|}{ Complex therapy $\mathrm{n}=31$} \\
\cline { 2 - 3 } & Traditional therapy $\mathrm{n}=21$ & $48,39 \pm 0,51$ \\
\cline { 2 - 3 } $\mathrm{CD} 3, \%$ & $48,24 \pm 0,49$ & $54,58 \pm 0,48^{*}$ \\
\hline \multirow{2}{*}{$\mathrm{CD} 19, \%$} & $51,33 \pm 0,48$ & $23,10 \pm 0,92$ \\
\hline \multirow{2}{*}{$\mathrm{CD} 4, \%$} & $24,00 \pm 0,99$ & $19,13 \pm 0,68^{* *}$ \\
\hline \multirow{2}{*}{$\mathrm{CD} 8 \%$} & $21,09 \pm 0,85$ & $29,35 \pm 0,31$ \\
\hline \multirow{2}{*}{$\mathrm{CD} 8$, cells/microlitre } & $29,09 \pm 0,42$ & $34,19 \pm 0,52^{*}$ \\
\hline \multirow{2}{*}{ IRI } & $31,62 \pm 0,43$ & $19,97 \pm 0,45$ \\
\hline \multirow{2}{*}{ IgA, g/l } & $19,71 \pm 0,43$ & $18,48 \pm 0,35$ \\
\hline \multirow{2}{*}{ IgM, g/l } & $18,33 \pm 0,20$ & $373 \pm 16$ \\
\hline \multirow{2}{*}{ IgG, g/l } & $364 \pm 16$ & $342 \pm 13$ \\
\hline \multirow{2}{*}{ CIC, y.e. } & $335 \pm 12$ & $1,49 \pm 0,04$ \\
\cline { 2 - 3 } & $1,46 \pm 0,04$ & $1,85 \pm 0,04^{*}$ \\
\cline { 2 - 3 } & $1,72 \pm 0,02^{*}$ & $2,74 \pm 0,06$ \\
\cline { 2 - 3 } & $2,76 \pm 0,09$ & $2,43 \pm 0,04^{*}$ \\
\cline { 2 - 3 } & $2,61 \pm 0,07$ & $1,77 \pm 0,03$ \\
\cline { 2 - 3 } & $1,83 \pm 0,03$ & $1,44 \pm 0,02^{*}$ \\
\cline { 2 - 3 } & $1,59 \pm 0,03^{*}$ & $18,83 \pm 0,61$ \\
\cline { 2 - 3 } & $19,18 \pm 0,62$ & $15,45 \pm 0,55^{*}$ \\
\cline { 2 - 3 } & $17,74 \pm 0,59$ & $30,74 \pm 1,18$ \\
\hline
\end{tabular}

Note: in the numerator - data before treatment;

In denominators - data after treatment

$\mathrm{p}$ - reliability of data with respect to indicators before treatment

$*_{-} \mathrm{p}<0,05 ; \quad *_{-} \mathrm{p}<0,01$

Table.3 The effect of the conducted therapy on immune status in patients with ulcerated leishmaniomas with tubercles of seeding with lymphangoites $(\mathrm{M} \pm \mathrm{m})$

\begin{tabular}{|l|c|c|}
\hline \multirow{2}{*}{ Indices of immunity } & \multicolumn{2}{|l|}{ Method of therapy } \\
\cline { 2 - 3 } & Traditional therapy $\mathrm{n}=6$ & Complex therapy $\mathrm{n}=16$ \\
\hline \multirow{2}{*}{$\mathrm{CD} 3, \%$} & $41,67 \pm 0,71$ & $45,56 \pm 0,94$ \\
\hline \multirow{2}{*}{$\mathrm{CD} 19, \%$} & $46,33 \pm 0,61$ & $53,25 \pm 0,89^{*}$ \\
\hline \multirow{2}{*}{$\mathrm{CD} 4, \%$} & $30,83 \pm 1,14$ & $26,50 \pm 1,56$ \\
\hline \multirow{2}{*}{$\mathrm{CD} 8 \%$} & $27,50 \pm 0,85$ & $19,12 \pm 0,81^{* *}$ \\
\hline \multirow{2}{*}{ IRI } & $29,17 \pm 1,14$ & $25,81 \pm 0,84$ \\
\hline \multirow{2}{*}{ IgA, g/l } & $32,83 \pm 0,94$ & $34,56 \pm 0,85^{*}$ \\
\hline \multirow{2}{*}{ IgM, g/l } & $19,50 \pm 0,62$ & $20,50 \pm 0,45$ \\
\hline \multirow{2}{*}{ IgG, g/l } & $19,50 \pm 1,26$ & $18,56 \pm 0,29$ \\
\hline \multirow{2}{*}{$\mathrm{CIC}, \mathrm{g}$.e. } & $1,48 \pm 0,09$ & $1,39 \pm 0,08$ \\
\cline { 2 - 3 } & $1,72 \pm 0,10^{*}$ & $1,86 \pm 0,05^{*}$ \\
\cline { 2 - 3 } & $2,62 \pm 0,03$ & $2,67 \pm 0,08$ \\
\cline { 2 - 3 } & $2,45 \pm 0,08$ & $2,35 \pm 0,05^{*}$ \\
\cline { 2 - 3 } & $1,90 \pm 0,07$ & $1,68 \pm 0,05$ \\
\cline { 2 - 3 } & $1,65 \pm 0,06$ & $1,43 \pm 0,05^{*}$ \\
\cline { 2 - 3 } & $24,70 \pm 0,90$ & $19,94 \pm 0,77$ \\
\cline { 2 - 3 } & $22,88 \pm 0,92$ & $17,23 \pm 0,64$ \\
\hline
\end{tabular}

Note: in the numerator - data before treatment; In denominators - data after treatment $\mathrm{p}-$ reliability of data with respect to indicators before treatment

$*_{-} \mathrm{p}<0,05 ; \quad * *-\mathrm{p}<0,01$ 
In patients treated with the traditional method, IRI rose 1.1 times, and in patients receiving the complex method of therapy, this index increased by 1.2 times.

In patients with ulcerated leishmanias against the background of traditional treatment, there was a tendency to decrease the relative content of CD19 cells compared to the data before treatment ( $p>0.05)$. And in patients receiving complex therapy after treatment, a significant decrease in the relative number of CD19 cells was detected $(\mathrm{p}<0.01)$.

After the treatment with the traditional method in blood serum in patients with ulcerated leishmanias, the $\operatorname{IgM}$ content significantly decreased $(\mathrm{p}<0.05)$ compared to the pre-treatment data, and the concentration of $\operatorname{IgA}$ and $\operatorname{IgG}$ remained at the data level before treatment $(p>0.05)$. And in patients receiving complex method of therapy, there was a significant decrease in the concentration of $\operatorname{IgA}, \operatorname{IgM}$ and $\operatorname{IgG}(\mathrm{p}<0.05)$ in relation to the data before treatment $(\mathrm{p}>0.05)$.

In patients of this group after treatment, both with traditional $(\mathrm{p}<0,05)$ and complex $(\mathrm{p}<0,01)$ method of therapy, there is a significant decrease in the serum concentration of the CIC in comparison with the data before treatment. The revealed decrease in the CIC index was more pronounced in patients treated with a complex method.

The results of the study show that the complex method of treatment of patients with ulcerated leishmaniomas has a positive effect on restoration of the revealed disorders in the immune system.

In subsequent studies, we investigated the effect of the conducted therapy on the status of immune status in patients with ulcerated leishmaniomas with tubercles of dissemination with lymphangitis.

In patients with ulcerated leishmanias with tubercles of seeding with lymphangites, the trend toward an increase in the relative number of CD3 cells of CD4 cells $(p>0.05)$ has been observed after traditional therapy, and after the completion of treatment with a complex method, a significant increase in the percentage of CD3 cells and CD4- cells compared with the data before treatment $(\mathrm{p}<0.05)$.

In both groups, the relative number of CD8 cells remained at the data level before treatment $(\mathrm{p}>0.05)$ (Table 3).
In patients treated with the traditional method, IRI increased by 1.2 times, and in patients receiving complex therapy this index increased by 1.3 times.

In patients of this group, after traditional treatment, there was a tendency to decrease the relative content of CD19 cells with respect to the data before treatment ( $p>0.05$ ). And in patients receiving complex therapy after the end of treatment, a statistically significant decrease in the relative number of CD19 cells was revealed $(\mathrm{p}<0.01)$.

After the end of treatment with the traditional method in serum in patients with ulcerated leishmaniomas with tubercles of dissemination with lymphangitis, the content of $\operatorname{Ig} \mathrm{A}, \operatorname{IgM}$ and $\operatorname{IgG}$ was prone to decrease ( $>0.05)$. And in patients receiving complex therapy, a significant decrease in concentration of $\operatorname{IgA}$ and $\operatorname{IgM}(\mathrm{p}<0.05)$ towards the data before treatment was detected, and the amount of $\operatorname{IgG}$ tended to decrease ( $p>0.05)$.

Patients of this group have a tendency to decrease after traditional therapy ( $p>0.05)$, and in case of complex therapy a significant decrease in serum concentration of the CIC is observed in comparison with the data before treatment $(\mathrm{p}<0.01)$.

The results of the study show that a complex method of treating patients with ulcerated leishmaniomas with tubercles of seeding with lymphangitis also has a positive effect on restoring the revealed disorders in the immune system, however, complete recovery of the revealed disorders is observed.

Thus, the complex method of therapy contributes to restoration of the revealed disorders in the immune system in patients with cutaneous leishmaniasis. It should be noted that this method of treatment has a more pronounced immunomodulatory effect in patients with mild form (tubercle form) of cutaneous leishmaniasis, and in patients with complicated forms (ulcerated leishmaniomas and ulcerated leishmanias with tubercles of dissemination with lymphangitis) of cutaneous leishmaniasis after treatment of complete recovery of disturbances in the immunity system is not observed and this indicates the need for a repeat course of therapy in this category of patients.

\section{References}

Abidova Z.M., and Ikramova N.D. 2014. Morbidity and clinical characteristics of patients with cutaneous 
leishmaniasis in Uzbekistan. Dermatovenereology and aesthetic medicine. Tashkent. 24 (3-4): 34-37.

Abidova Z.M., Rakhmatov A.B., Izvekova O.V., Baynazarov N.B. 2014. Immunocytokine status of patients with cutaneous leishmaniasis. Journal of theoretical and clinical medicine. Tashkent. 2 (3): 8.

Abidova Z.M., Nabiyev T.A., Abdurakhmanova N.A., Alimjanov J.A. 2017. Current situation and clinical course of cutaneous leishmaniasis in Uzbekistan. Dermatology and aesthetic medicine. 2 (34): 93.

Fighting against leishmaniasis. 2010, March 22-26. Report at the meeting of the WHO Expert Committee on Leishmaniasis. WHO Technical Report Series. No.949, Geneva. 243.

Djumagulov K.B., Rapoport L.P., Yeliseyev L.N., et al., 1989. Zoonotic cutaneous leishmaniasis in Chimkent region. Healthcare of Kazakhstan. 1: 4546.

Zalaliyeva M.V. 2004. Methods for assessing subpopulations of peripheral blood lymphocytes in humans. Method. recommendations. Tashkent. 15.

Ponirovsky E.I. 1993. Parasitic systems of leishmaniasis and epidemiological zoning: Abstract. diss.Dr. med. science. Moscow. 3.
Ponirovsky E.N., Strelkova M.V., Sergiyev V.P., Baranets M.S. 2016. Mapping of focal areas as a basis for prevention of zoonotic cutaneous leishmaniasis. Medical parasitology and parasitic diseases. M. 1: 57-59.

Strelkova M.V., Yeliseyev L.M., Ponirovsky E.N., et al., 1993. Isoenzyme identification of isolates of leishmania isolated from large gerbils, mosquitoes and sick people in zoonotic cutaneous leishmaniasis in Turkmenistan. Med. parasitol. and parasitar. disease. 5: 34-37.

Buffet P., Caumes E., Gentilini M. 1994. Traitement des leishmanioses cutanees localisees. Ann. Dermatol. Venereol. 121: 503-511.

Digeon M., Zaver M., Riza I., Bach I.F. 1977. Detection of circulating immune complexes in human sera by simplified assays whit polyethylene glycol. $J$. Immunol. Metods. 16: 165-183.

Mancini I., Carbonara A.O, Aeromans J.F. 1965. Immunochemical guantiration of antigen by single radial immunodiffusion. Immunochemistry. 2: 235248.

Olliaro P.L., and Brycesson A.D. 1993. Practical progress and new drugs for changing patients of leishmaniasis. Parasitol. Today. 9: 323-328.

\section{How to cite this article:}

Raximov I. R. 2018. Investigation of the Effect of Conducted Therapy on the State of the Immune System in Patients with Cutaneous Leishmaniasis. Int.J.Curr.Res.Aca.Rev. 6(6), 65-70.

doi: https://doi.org/10.20546/ijcrar.2018.606.009 